\title{
Uma análise neo-institucional da adoção de jointness pelos Estados Unidos
}

\section{An neo-institutional analysis of jointness adoption by the United States}

Rev. Bras. Est. Def. v. 7, nº 1, jan./jun. 2020, p. 125-149

DOI: $10.26792 /$ RBED.v7n1.2020.75181

ISSN 2358-3932

MARIA EDUARDA LARYSSA SILVA FREIRE MARIANA PIMENTA OLIVEIRA BACCARINI

\section{INTRODUÇÃO}

A evolução nos assuntos militares tem cada vez mais inserido o conceito de jointness ${ }^{1}$ na discussão e no escopo de visão das Forças Armadas (Österberg 2004). Na década de 1990, com o avanço das tecnologias militares, foi possível perceber uma maior capacidade de integração entre as diferentes dimensões do poder militar: mar, terra e ar. $\mathrm{O}$ pensar conjunto foi sendo cada vez mais desenvolvido a partir da Revolução dos Assuntos Militares (RAM) ${ }^{2}$ que, nos Estados Unidos, teve início na mesma década (Sloan 2008). A necessidade de integrar forças ganhou ainda mais reconhecimento como forma de facilitar as ações de cunho militar, e a partir disso, a interoperabilidade ${ }^{3}$ e a compatibilidade ganharam ênfase, passando a serem fortemente valorizadas nesse cenário.

O ponto é, a natureza das guerras atuais demanda essencialmente o emprego de jointness nas estruturas institucionais de defesa, reconhecendo que também nos momentos de paz a sua prática deve ser constante (Marquis et al. 2017). No entanto, é importante notar que a incorporação dessa prática

\footnotetext{
Maria Eduarda Laryssa Silva Freire - Mestranda no Programa de Pós-Graduação em Ciência Política e Relações Internacionais (PPGCPRI/UFPB) e bacharel em Relações Internacionais pela Universidade Federal da Paraíba (UFPB). Pesquisadora membra do Grupo de Pesquisa em Estudos Estratégicos e Segurança Internacional (GEESI/UFPB/CNPq).

Mariana Pimenta Oliveira Baccarini - Professora Adjunta da Universidade Federal da Paraíba, Departamento de Relações Internacionais. Leciona no Curso de Graduação em Relações Internacionais e na Pós-Graduação em Ciência Política e Relações Internacionais. Doutora em Ciência Política pela UFMG (2014), Mestre (2010) e Graduada (2005) em Relações Internacionais pela PUC-MG e Especialista Estudos Diplomáticos pela Faculdade Milton Campos (2007). Possui Pós-Doutorado em Relações Internacionais, tendo por linha de pesquisa Processos Decisórios em Política Externa e Internacional na Pontifícia Universidade Católica de Minas Gerais (2014).
} 
se deu e se dá de forma diferente a depender do país e do contexto tanto interno quanto externo. Assim, para entender quais os elementos que influenciaram a instituição de defesa dos Estados Unidos, tido como um dos países pioneiros a incorporar jointness em suas Forças Armadas, o presente artigo se divide nas seguintes etapas:

Primeiro, buscar-se-á adensar no que compreende o conceito de jointness, analisando aspectos relevantes e característicos desse processo; segundo, analisaremos como o arcabouço teórico sobre instituições entendem a mudança institucional, lançando luz sobre possíveis maneiras de interpretar o processo referente ao caso dos Estados Unidos; na terceira parte do artigo o objetivo é o de realizar uma explanação sobre quais bases jointness se inseriu no país e como as instituições se moldaram para recebe-lo, compreendendo os meandros desse processo, ao tentar fazer a correlação necessária; e, por fim, será concluído elencando elementos que apontam para a relevância do aspecto institucionalista dentro de todo esse contexto.

Acerca do procedimento metodológico, caracterizado principalmente por ser qualitativo, descritivo e analítico, o estudo do caso dos EUA permitirá adensar em aspectos relevantes da análise institucional do órgão de defesa do país, tendo em vista a análise do percurso de mudança percorrido pelo Departamento de Defesa dos Estados Unidos (DoD) para se tornar capaz de realizar operações conjuntas como objetivo geral. Assim, por meio da revisão bibliográfica, será mapeada a discussão sobre jointness e mudança institucional, bem como será traçada uma trajetória histórica acerca de institucionalização desse processo nos Estados Unidos, permitindo que seja construído um entendimento sobre a relação entre essa trajetória e o que se entende por mudança institucional, para concluir apontando quais foram os aspectos institucionais relevantes para a incorporação do jointness no país.

\section{ORIGEM E DEFINIÇÕES DE JOINTNESS}

Na prática, jointness remete a um processo bastante antigo que, nos seus primórdios, remonta à tentativa de ação conjunta entre a força terrestre e a força marítima, como percebido na Antiguidade, e que até hoje é visto com grande relevância. Por ser antigo, seria um erro associar jointness meramente com as guerras da nova era (Pessoa and Freitas 2015, 206). Esse não é um processo linear de conceito único. Ao longo do tempo, tornou-se possível perceber o surgimento de diversas modalidades e percepções, bem como de avanços e de retrocessos. Sua definição, por diversas vezes, pode ser complexa. Principalmente por ser um debate contínuo, fazendo surgir assim diferentes formas de defini-lo (Österberg 2004). 
Mas, então, ao que de fato se refere quando se fala de jointness principalmente no meio militar? Esse conceito, aplicado em diversas doutrinas e utilizado como ferramenta importante para condução da guerra, consiste na aplicação do poder dos diferentes ramos das Forças Armadas, isto é da Marinha, do Exército, e da Força Aérea, de forma que eles se apoiem mútua e combinadamente, "[ $[.$.$] consistindo de oficiais de diferentes ra-$ mos, com conhecimentos especiais sobre seus correspondentes serviços" (Österberg 2004, 12, tradução nossa). Vitale (1995) é ainda mais preciso ao desenvolver uma definição que coloca jointness como sendo sinônimo de operações militares conjuntas, capazes de tornar a capacidade militar maior do que quando apenas uma das forças é empregada.

"Semelhança, sinergia, doutrina conjunta e interoperabilidade" (Wilkerson 1997, 1, tradução nossa) são palavras-chave que melhor explicariam jointness. No entanto, para que estes elementos sejam alcançados, é necessário que o efetivo militar seja bem treinado de maneira a conseguir aplicar conjuntamente suas capacidades específicas. Assim, um dos pilares é a unidade de esforços, que, associada com a coordenação dos diferentes ramos e suas habilidades particulares de mar, terra e ar, oferece aos comandantes uma multidimensionalidade de capacidades que permitem apresentar ainda mais resultados:

Capacidades múltiplas dos ramos permitem que um Comandante da Força Conjunta combine capacidades conjuntas, táticas, técnicas, e procedimentos tanto de maneiras assimétricas quanto simétricas, sincronizadas para produzir um impacto militar total maior do que a soma de suas partes (Vitale 1995, 27, tradução nossa).

Sendo assim, quais os efeitos que este conceito implicaria na prática? $\mathrm{O}$ mais importante, de acordo com Österberg (2004), é a organização de capacidades distintas, empregando habilidades tanto de mar quanto de terra e de ar, cujo impacto em determinada operação militar deveria ser grande e positivo. Para Wilkerson $(1997,1)$, o entendimento e a confiança mútua são elementos fundamentais e que dariam consistência à ideia de time para a joint warfare. Isso ocorreria por meio da aplicação de táticas, técnicas e procedimentos comuns, basilares para o sucesso da operação militar, estando estes diretamente relacionados à competência do serviço realizado pelos militares. Tendo tudo isso em vista, é importante considerar jointness como algo que demanda planejamento, organização, e não como algo que simplesmente acontece.

Essa concepção teve uma difusão mais ampla no período do pós-Guerra Fria, no contexto da Organização do Tratado do Atlântico Norte, quando se percebeu a necessidade de intensificar o combate às ameaças apresen- 
tadas pela nova conjuntura mundial. Nesse contexto, agilidade, ganhos na distância e no tempo, bem como a interoperabilidade, operações conjuntas expedicionárias, operações humanitárias simultâneas e mobilidade, passaram a ser algumas das ferramentas e práticas consideradas como cruciais para potencializar o sistema de Defesa da Aliança (Sloan 2008).

Ademais, é importante ter em consideração que, apesar das divergentes perspectivas sobre jointness, há um consenso sobre a necessidade de uma maturação organizacional para a sua realização plena (Pessoa and Freitas 2015). E que, de acordo com Vitale (2005), uma das áreas que tem impacto direto na realização deste é justamente a das organizações de defesa, isto é, as instituições que diretamente detêm o controle dos processos que afetam as operações militares conjuntas. A percepção do processo como sendo um modelo de método operacional ocorreu, de fato, quando, a partir de uma reforma no legislativo dos Estados Unidos, instaurou-se o Goldwater-Nichols Act (GNA) (Pessoa and Freitas 2015), que será melhor detalhado em momentos posteriores.

O tópico seguinte, por sua vez, buscará apresentar a mudança institucional sob os enfoques neoinstitucionalistas, como forma de apresentar como se tem discutido esse tema ainda que muito pontualmente, além de dar subsídios para se analisar o caso em questão.

\section{A MUDANÇA INSTITUCIONAL À LUZ DOS NEOINSTITUCIONALISMOS}

A literatura sobre mudança institucional possui diversos vieses, e o novo institucionalismo vem justamente se debruçando de maneira mais analítica no que diz respeito aos seus estudos. Por não ser um campo linear e unificado, existem percepções que divergem. Tais diferenças são atualmente representadas pelos novos institucionalismos da escolha racional, o sociológico e o histórico, que se preocupam, dentre outras coisas, com entender a mudança institucional de maneira renovada (Nascimento 2009).

Ao refletir sobre essas três abordagens, Thelen (1999) entende que existe uma diversidade interna inerente a cada uma delas que permite diferenciá-las. Na perspectiva do institucionalismo da escolha racional, é possível perceber, dentre as principais características, a busca pelo equilíbrio, que seria possibilitado pela estrutura das instituições, o qual proporcionaria aos atores ganhos específicos. Nesse caso, é levado em consideração a maneira como as preferências dos atores vão moldando o jogo, de forma a fazer prevalecerem seus interesses - enquanto, no institucionalismo sociológico, o viés está mais voltado para uma percepção de que as instituições moldariam o comportamento e as práticas dos indivíduos. E, por fim, o institucionalismo histórico, que, apesar de abarcar também a compreensão 
sobre como as instituições acabam por moldar os interesses, as estratégias, bem como os comportamentos e práticas dos atores, dedica-se a analisar aspectos atrelados à origem das instituições, consequentemente estando voltado a uma abordagem mais histórica (Thelen and Conran 2016).

Convém esclarecer que a mudança institucional é uma abordagem considerada como muito nova nos estudos que tratam de instituições. Esse é um tema que, apesar de tudo, ainda vem sendo tateado paulatinamente. Por isso, algumas abordagens vão ser mais consideradas do que outras. Todavia, não deixaremos de fazer uso das últimas. No presente estudo, fica evidente que a abordagem do institucionalismo histórico consegue explicar melhor o caso, uma vez que se analisa todo um contexto que engloba importantes variáveis do processo histórico. Mas, ainda assim, o caso será também analisado à luz do institucionalismo da escolha racional e do sociológico, entendendo-se que, a partir disso, uma gama maior de elementos pode ser abarcada pela análise neoinstitucionalista.

Contudo é importante observar que, em grande parte, estes institucionalismos tendem a observar as instituições a partir da ótica da sua emergência e da sua prevalência, ou seja, as instituições como estáveis (Thelen 1999). Sendo assim, a proposta do presente artigo vai, em alguma medida, contra isso, uma vez que observa uma ruptura, um contexto de reforma dentro de uma instituição, onde se entende relevante analisar também contextos de mudanças institucionais.

\section{Uma abordagem gradual/incremental da mudança institucional}

Brousseau (et al. 2011) entende que a mudança institucional, quando se trata de regras formais, ${ }^{4}$ é fruto de um confronto que engloba, por muitas vezes, coalizões de agentes, conflitos e barganha, que buscam promover novas regras, enquanto há outros atores que tentam favorecer o status quo da instituição, podendo estas serem criadas endogenamente ou importadas - o que se relaciona diretamente com a maneira como a abordagem do institucionalismo da escolha racional vê as coisas.

No que diz respeito à implementação da reforma dessas regras ou instituições, os reformuladores podem se deparar com dois tipos de restrições: o primeiro diz respeito às restrições ex ante, relacionadas à viabilidade da reforma. Nesse caso, o processo de tomada de decisão pode ser bloqueado antes das reformas serem aceitas. Enquanto o segundo tipo compreende as restrições ex post, que estão atreladas à reação negativa e a reversão das reformas após realizada a sua implementação (Brousseau et al. 2011). Os grupos que reagem com resistência frente às mudanças das regras geralmente são aqueles que de alguma forma tiram proveito da situação do jeito 
que ela já é, ou aqueles que têm receio devido à dificuldade de se prever os resultados destas (Steinmo 2008).

A literatura entende a gestão conjunta como questão-chave para evitar os possíveis entraves nas reformas, buscando o estabelecimento favorável destas. Além da importância de ter bastante claro as possíveis consequências caso esta seja implementada, uma vez que o resultado sub-ótimo dessas reformas poderia levar a instabilidade dentro da instituição (Brousseau et al. 2011). Essa abordagem está diretamente relacionada com a perspectiva dos institucionalistas da escolha racional, que tendem a enxergar as instituições a partir do cálculo estratégico, onde um resultado sub-ótimo negaria o melhor resultado para a coletividade (Hall and Taylor 2003). E, como ressaltado no final do parágrafo anterior, foi possível observar-se atritos dentro do setor militar após a reforma. O que está relacionado diretamente com os resultados sub-ótimos obtidos, e salientado por Brousseau et al. (2011) como uma consequência possível de situações em que a ausência de gestão conjunta pode causar ao processo e à mudança propriamente dita.

Weyland (2008) defende a importância de se pensar as instituições para além de pressupostos estáticos e lineares, uma vez que estes prejudicariam um entendimento mais elaborado sobre o que de fato se trata mudança institucional. A crítica do autor aos institucionalismos histórico e da escolha racional $^{5}$ se refere a tal limitação, uma vez que estes teriam "enfatizado a inércia e a persistência, além de ter conceituado a mudança institucional como um caminho mais ou menos constante ao longo de uma trajetória pré-definida" (281, tradução nossa). Entre as razões, pode-se mencionar o fato de que determinado número de atores, que se beneficiaria de um arranjo específico, poderia dificultar a busca pela mudança. No entanto, o argumento sobre a necessidade de dinamismo na análise das instituições prevalece.

Do lado de quem demanda a mudança institucional, os atores podem demonstrar certa aversão ao risco frente a um contexto de reformas. Isto é, com cautela, estes preferirão realizar uma mudança institucional que implique pequenos benefícios imediatos do que uma mudança que sugira a possibilidade de maiores benefícios, uma vez que há chances de acabar não havendo o retorno esperado. Assim, os ganhos são buscados com certo grau de prudência, onde os esforços são geralmente limitados. A preferência pelo status quo está diretamente relacionada com o fato de que diversas das consequências decorrentes da mudança institucional podem ser condutoras de perdas; assim, a aversão ao risco conduziria a uma situação de equilíbrio pontuado, mesmo com as chances de ganho (Weyland 2008).

Do lado da oferta da mudança institucional, o que pode ser depreendido é que esta precisa ser aplicável e vista como promissora. As reformas precisam apresentar soluções que sejam consideradas pertinentes, por isso 
é comum que experiências estrangeiras ${ }^{6}$ sejam adotadas como parâmetro de implementação, o que pode acabar gerando ondas de mudanças, que é quando uma mudança ocorre e em seguida vai afetando e influenciando outros referenciais. "Mudanças drásticas em um país frequentemente estimulam esforços de replicação em outras nações, chamando a atenção para problemas e oferecendo ideias para soluções" (Weyland 2008, 290, tradução nossa).

Thelen e Conran (2016) vão chamar atenção para as crescentes necessidades de modificação dentro de instituições já pré-estabelecidas, principalmente à luz da mudança gradual/incremental. $\mathrm{O}$ institucionalismo histórico de maneira geral possui uma visão de que as instituições tendem a seguir determinada lógica condicionada pelo path dependency, ${ }^{7}$ até o momento em que ocorre uma critical juncture $^{8}$ e, a partir disso, a estabilidade é interrompida por alguma mudança institucional.

$\mathrm{O}$ institucionalismo histórico de Thelen busca focar nesses elementos, tendo como base o processo temporal das instituições, para ajudar a entender como estas teriam sido desenvolvidas, bem como a compreender as suas mudanças. Isto por "enxergar as instituições como um legado de processos históricos concretos” (Thelen 1999, 382, tradução nossa). Portanto, acredita-se que as instituições estão relacionadas ao contexto, onde tanto aspectos de continuidade quanto de mudança devem receber atenção para que seja possível entender os arranjos institucionais - nos moldes do Weyland (2008), compreendendo uma visão institucional dinâmica e não estática.

Como colocado por Baumgartner e Jones (1993, apud Gomide 2014, 858), é a partir disso que alguns estudiosos vão buscar:

[...] trabalhar padrões de mudanças institucionais alternativos aos modelos de "equilíbrio pontuado", nos quais os longos períodos de estabilidade institucional seriam interrompidos por momentos de mudanças concentradas (transformações radicais, promovidas por fatores exógenos), seguidas por novo período de estabilidade até que uma nova conjunção crítica ocorra.

Isto porque esse modelo de transformação abrupta, isto é, em casos de "equilíbrio pontuado", não permitiria enxergar as fontes endógenas de mudança institucional - provocando um tipo de entendimento de que a reforma só seria possível a partir do colapso de todo um conjunto de instituições, fazendo necessário a substituição por um novo (Mahoney and Thelen 2009).

Dessa forma, apresentando um contraponto à ideia da estabilidade, Mahoney e Thelen (2009) vão defender que as instituições tendem a mu- 
dar ao longo do tempo. E vão chamar a atenção para a possibilidade de que a mudança possa vir a ser sutil e gradual. "Mudanças graduais podem ter grande importância; bem como seus desdobramentos graduais podem ser de suma importância ao implicar outros resultados" (3, tradução nossa).

É possível dividir os tipos de mudança gradual em quatro dimensões: displacement diz respeito a substituição de regras antigas por regras novas, podendo ocorrer tanto de forma abrupta, geralmente através de revolução, quanto gradual, onde as regras antigas competem com as novas; layering faz menção a incorporação de novas regras que passam a estar acima ou lado a lado das pré-existentes, nesse caso as novas não substituem as antigas normas; ao invés disso, elas estão relacionadas, mas o comportamento é alterado em alguma medida a partir da nova regra; drift se relaciona com a mudança no impacto que as regras existentes possuíam, ocasionado por uma alteração no ambiente, geralmente decorrente de condições externas; e a conversion refere-se a uma modificação na promulgação das regras que já existem, como forma de estabelecer uma nova distribuição estratégica (Mahoney and Thelen 2009).

\section{A análise institucional atrelada às abordagens organizacionais: cultura e aprendizado dentro de instituições}

Quando pensado um viés voltado para o institucionalismo sociológico, algumas abordagens podem ser úteis. As abordagens organizacionais podem servir de forma mais precisa quando o objetivo é analisar processos dentro de uma instituição de defesa, foco do caso que será analisado em seguida - principalmente no entendimento sobre mudanças e dinâmicas relacionadas à evolução e transformação dessas (Pessoa 2017). Uma das perspectivas que pode ser aqui adentrada é a que trata da Cultura Organizacional, onde entende-se a própria cultura militar como sendo uma variável crucial para a mudança institucional.

A cultura organizacional refere-se à forma como o aprendizado é particular para cada uma das forças, o que desemboca na transformação de instituições militares no sentido de determinar como certa mudança vai acabar sendo implementada (Pessoa 2017). Uma outra perspectiva dentro das teorias organizacionais é a que entende a Mudança Militar como Aprendizado Organizacional, a partir da qual se observa uma perspectiva sociológica e se entende que a reforma partiria principalmente do aprendizado decorrente de experiências passadas (Pessoa 2017).

Quanto à mudança organizacional ser dada mediante aprendizado se constrói por meio da mudança de Doutrina. Um ciclo de apren- 
dizado se instaura, de forma que as ações individuais, em conjunto com a atenção aos eventos que se sucedem, permitem a identificação dos problemas e/ou lacunas existentes, possibilitando que alterações sejam realizadas no âmbito da Doutrina a fim de "atualizá-la" (Pessoa 2017: 87).

Segundo Hall e Taylor (2003), o institucionalismo sociológico, por sua vez, reflete essas questões ao salientar que muitas das práticas e dos procedimentos que são adotados pelas organizações modernas consistem em procedimento e práticas culturais, baseados em valores dentro de um ambiente cultural, em que os atores que promovem as mudanças "tomam de 'empréstimo' elementos dos modelos de instituição existentes" (Hall and Taylor 2003, 217). A mudança, sobretudo, advém da "convergência entre as instituições e o cenário histórico-social” (Nascimento 2009, 108).

Tendo em vista esse panorama geral sobre a literatura acerca de mudança institucional, em seguida será adentrado no caso específico dos Estados Unidos, para entender os entremeios do processo da institucionalização do jointness no DoD, estabelecendo uma relação com o que foi apresentado nesse subtópico. Assim, busca-se abordar, principalmente a partir de um viés institucionalista, as falhas que resultaram na falta da capacidade de interoperar.

\section{O PIONEIRISMO DOS ESTADOS UNIDOS}

Nos Estados Unidos, os esforços no sentido de realizar uma reforma no comando e nas estruturas das forças militares e do DoD não são recentes. Nos idos da Segunda Guerra Mundial já se pensava nisso. Antes mesmo do Departamento ser estabelecido, já era possível enxergar importantes figuras, tanto militares quanto civis, pensando sobre como as diferentes forças poderiam serem unificadas. O Joint Chiefs of Staff (JCS) foi criado, em 1942, frente às condições deixadas pelo ataque a Pearl Harbor. Os Estados Unidos se viram em uma situação na qual se fazia necessário a adoção de planos estratégicos e logísticos coordenados tanto entre as forças quanto entre os seus aliados. Cabe pontuar que a autoridade principal esteve, nesse período, relegada ao Presidente. Cinco anos após, foi instituído o National Security Act com o propósito de unificar todas as forças sob a competência de um único departamento, e a partir do qual ficou estabelecido que os diferentes ramos das Forças Armadas passariam a responder ao Secretário de Defesa. Posteriormente o National Military Establishment, estrutura unificada decorrente desse decreto, viria a ser renomeado de Department of Defense (Carter 2016; Rearden 2012; DoD 2020). 


\section{O Goldwater Nichols Act e a institucionalização da prática de jointness}

Um dos grandes marcos no DoD, principalmente no que diz respeito à incorporação do jointness às Forças Armadas, foi o Goldwater-Nichols Department of Defense Reorganization Act datado de 1986. Este representou uma reforma na legislação do país que alterou a maneira como o Departamento funcionava, consequentemente levando a mudanças na consecução das operações militares, além de ter sido, até então, a maior reformulação desde a criação da instituição em 1947 (Marquis et al. 2017).

Dentre o que ficou estabelecido a partir da reforma, nos âmbitos das doutrinas, dos treinamentos e da educação militar, destacou-se a necessidade de desenvolver uma doutrina que desse prioridade ao emprego conjunto das Forças Armadas, de serem formuladas políticas voltadas para o adestramento conjunto das forças singulares e de coordenação da educação e treinamento destas. Sendo assim, caberia à Segurança Nacional prover estas forças de "(1) direcionamento estratégico unificado para as forças combatentes; (2) operações sob comando unificado; e (3) integração em uma equipe eficiente composta das forças terrestres, navais e aéreas" (EUA 1986, 1, tradução nossa).

No entanto, as bases para essa reforma não surgiram ao acaso. $\mathrm{O}$ que foi vivenciado durante a Segunda Guerra Mundial deu bastante força para a instituição do jointness no seu sentido mais puro, isto devido ao fato de que as experiências da guerra demonstraram as vantagens de agir em conjunto e as desvantagens de não haver a busca pela unidade de esforços (Armstrong 1995; Pessoa 2017) . Assim, o Joint Chiefs of Staff ${ }^{\circ}$ dos Estados Unidos, que, na sua composição atual, conta com um Presidente, um Vice-Presidente, o Chefe do Estado Maior do Exército, o Chefe do Estado Maior das Operações Navais, o Chefe do Estado Maior da Força Aérea, o Comandante do Corpo de Fuzileiros Navais e o Chefe da Guarda Nacional (EUA 2016), deu todo o suporte necessário para enfatizar a importância que o conceito de jointness representava para as operações de cunho militar, principalmente através de discursos oficiais (Armstrong 1995).

Entretanto, o avanço do jointness mostrou-se bastante lento. Através da tentativa de criação, no pós-guerra, de um sistema de comando unificado, era possível perceber uma ambiguidade no que diz respeito ao desenvolvimento deste, uma vez que a questão da rivalidade intraforças ainda era bastante latente. A insatisfação pela falta de coordenação entre os comandos levava sempre a uma tentativa de organizar e exercitar a unidade de esforços no teatro de operações. No entanto, o problema maior se concentrava em conseguir centralizar o controle das forças sem que interferissem 
nas prerrogativas fundamentais do comando de cada uma delas de forma particular (Armstrong 1995).

A derrota na Guerra do Vietnã foi um dos eventos importantes para a instituição do GNA. As falhas e as deficiências operacionais percebidas no conflito e o mau desempenho das forças, muito decorrentes da falta de cooperação intraforças, serviram como fatores que impulsionaram esse processo de reorganização do nível de tomada de decisão militar dos Estados Unidos. Nesse sentido, estas falhas e deficiências foram cruciais para que a legislação fosse aprovada em prol de prevenir o país de complicações futuras no que tange ao planejamento e emprego de força (Bourne and 1998; LoPresti 1991).

Posteriormente, em 1979, numa tentativa de resgatar 66 cidadãos americanos que, após um ataque à embaixada estadunidense no Teerã, estavam sob o domínio de um grupo de militantes devotos ao então Ayatollah, Ruhollah Khomeini, o DoD empregou a missão Eagle Claw, que fracassou. Entre as razões identificadas para este fracasso estavam o treinamento separado que as unidades militares tiveram, bem como problemas relacionados à hierarquia do setor de comando e controle, além da falha nos equipamentos de interoperabilidade entre as diferentes forças (Marquis $e t$ al. 2017). O abortamento da missão por parte dos comandantes que lideravam a missão conduziu à percepção de que os Estados Unidos não estavam devidamente preparados para operações conjuntas (Hamre 2016).

Já em 1983, por sua vez, foi instaurada a missão Urgent Fury ${ }^{11}$ quando 650 estudantes de medicina americanos se viram ameaçados na ilha de Granada por um golpe de estado que ocorrera (Marquis et al., 2017):

A percepção de que o Departamento de Defesa sofria de problemas estruturais foi reforçada pela Operação Urgent Fury, quando os Estados Unidos invadiram a pequena nação caribenha de Granada. O Corpo de Fuzileiros Navais e o Exército efetivamente dividiram a ilha e conduziram operações paralelas isoladamente. Os comandantes não podiam se comunicar porque os rádios não eram interoperáveis. Circulavam histórias sobre oficiais militares usando telefones comerciais para se comunicarem e se reportarem (Hamre 2016, 1, tradução nossa).

Apesar do resultado dessa operação ter sido positivo, houve várias falhas de comunicação e equipamentos que tornaram difícil a coordenação das forças aérea e naval, e que poderiam ter culminado em um desastre. Após esses episódios, o congresso aprovou o que viria a ser a maior reorganização no DoD desde a sua criação (Marquis et al. 2017).

Para alguns, os problemas vistos nestas situações, muito relacionados à falta de coordenação de esforços, estariam diretamente conectados com a 
questão da rivalidade intraforças, originada por interesses, culturas e doutrinas organizacionais distintos e, por consequência, conflitantes, de cada um dos ramos das Forças Armadas. Percebeu-se assim que a estrutura do DoD preconizava muito mais as necessidade e prioridades individuais das forças singulares. Isso, em alguma medida, estimulava a rivalidade intraforças e conduzia a diversas falhas nas operações militares (McInnis 2016).

Para Snider (1996), o GNA surge justamente como a busca pelo amadurecimento das relações militares e também do que seria de fato jointness. Há uma modificação nos papeis tanto das forças quanto dos seus Comandantes, suas funções são fortalecidas e o Joint Chiefs of Staff passa a atuar em conjunto com os comandos unificados nos planejamentos e programações das novas capacidades militares. Assim, com base em determinado grau de cooperação, as forças formularam a estratégia militar, uma doutrina conjunta, o design e a implementação dos treinos coordenados e suas avaliações.

Assim, atualmente, a responsabilidade de aconselhar o Presidente está ancorada no Chefe de Estado-Maior Conjunto, dotado de maiores capacidades analíticas no que concerne às áreas de planejamento estratégico, bem como de logística e doutrina conjunta, tirando a responsabilidade dos comandantes das forças, que anteriormente estavam no topo da cadeia de comando. A estes foi dada a responsabilidade de treinar e equipar as forças com bases na ação conjunta, enquanto aos Comandos Combatentes Unificados, capacitados com maior poder e influência, delegou-se a competência de determinar os treinamentos conjuntos, bem como de organizar e empregar as forças que estariam sob seu comando. Isso serviria, além de tudo, também para diminuir, em algum grau, a influência que os comandantes das forças singulares teriam (Pires et al 2018; McInnis, 2016).

No que tange às forças singulares de maneira direta, pode-se perceber que a questão da educação militar e exigências atreladas à formação passaram também a receber destaque importante, uma vez considerado que a qualificação profissional com vistas à cultura conjunta passou a ser requisito fundamental no perfil militar daqueles que estariam à frente de comandos conjuntos. Essa conjuntura, inclusive, "forçou as Forças Singulares a designar para tais cargos alguns de seus melhores quadros" (Pires et al 2018, 214). Além disso, teriam sido aumentados os estímulos aos militares que desempenhassem funções dentro dos comandos conjuntos, através de melhores recompensas e capacitações.

Dessa forma, as estratégias que anteriormente eram individuais e muitas vezes incompatíveis, assim como as doutrinas que eram executadas de formas distintas por cada uma das forças e os treinamentos normalmente individuais, passaram a ser formulados conjuntamente, e a partir disso os 
diferentes ramos das Forças Armadas começaram a responder a uma estrutura de comando unificado (Snider 1996). O objetivo não era o de excluir as particularidades e as filosofias de cada um. O que se esperava era a capacidade de condensar as características destes de forma que cada força pudesse complementar a outra (Trainor 1993).

\section{Uma análise acerca da mudança institucional decorrente do Goldwater Nichols Act}

$\mathrm{Na}$ sua origem, aproximadamente uma década antes de ser realmente aprovado, o GNA surgiu em um contexto controverso, advindo da percepção, principalmente por parte de um número diminuto de oficiais e do Congresso, de que o setor militar dos EUA estava tendo problemas em sua capacidade de operar de maneira conjunta. Ademais, os problemas se mostravam sistemáticos e não apenas relacionados a falhas de indivíduos específicos. Assim, quando do início, dois atores se mostraram fundamentais para o processo de instituição de jointness. A saber, os senadores Samuel Nunn e Barry Goldwater, ${ }^{12}$ que trouxeram à tona os principais problemas já citados anteriormente (Nemfakos et al. 2010), e sofreram recusas das Forças Armadas, principalmente dos serviços da Marinha e dos Fuzileiros Navais, quanto a qualquer mudança.

Desse modo, é possível afirmar que inicialmente houve uma ausência de gestão conjunta no que diz respeito ao processo do GNA. A legislação apresentada por senadores estadunidenses foi recebida principalmente com resistência por parte do setor militar do país. Portanto, nota-se que os trâmites do processo sofriam de falta de consenso desde o seu início, o que se explica principalmente pela existência de ideias divergentes no que tange aos principais desafios para o DoD acerca da forma como este se organiza e opera. Muitas das percepções dos especialistas de defesa estavam pautadas em experiências e prioridades próprias (McInnis 2016). O que tem relação direta com o que Steinmo (2008) e Weyland (2008) entendem sobre os grupos que relutam em mudar algo, sendo estes geralmente atores que se beneficiam de alguma maneira da configuração existente e demonstram aversão ao risco. A relutância, em particular da Marinha e dos Fuzileiros Navais, era justamente devido à crença de que, uma vez que a legislação fosse aprovada, as suas habilidades de fazer guerra sofreriam degradação (McInnis 2016). A resistência dizia respeito principalmente ao efeito de redução de poder dos chefes das forças singulares, isto é, estes passariam a ser aconselhadores secundários.

Além disso, as resistências poderiam surgir por conta dos desafios no que diz respeito à institucionalização do processo de operação conjunta. 
Aliado a isso, a mudança dessa instituição demandou inclusive uma alteração quanto ao perfil dos oficiais e do modelo de ensino empregado (Pessoa 2017), como apontado anteriormente. Quando considerados elementos como o paroquialismo e a cultura individual destes, os desafios se tornam ainda mais latentes e prováveis de desembocar em possíveis resistências quanto à reforma buscada. A título de exemplo, alguns problemas puderam ser evidenciados dentro do Pentágono por aproximadamente dois anos, que diziam respeito à aceitação de alguns serviços do órgão sobre suas respectivas funções delegadas, principalmente no que tange aos treinamentos das forças e do efetivo reserva — atrito que só foi resolvido no fim de 1994 (Snider 1996).

Anterior à reforma, o que se via dentro do Departamento eram diversas cadeias de comando que acabavam sendo confusas, além de um planejamento precário entre as forças, conduzindo a uma fraca coordenação entre elas. Assim, frente a situações de crise, as respostas eram dadas de maneira ad hoc. O que é extremamente problemático dado a busca por integração e unidade, e explica também o contexto em que muitas vezes as distintas forças falhavam em se comunicar. Soma-se a isso, ainda, as rivalidades intraforças e o paroquialismo ${ }^{13}$ (Nemfakos et al. 2010).

À luz do institucionalismo da escolha racional, é possível dizer que a maneira como os comandantes das forças singulares se comportavam, previamente à aprovação da reforma, condiz com atitudes de atores que "compartilham um conjunto determinado de preferências ou de gostos e se comportam de modo inteiramente utilitário para maximizar a satisfação de suas preferências" (Hall and Taylor 2003, 205), configuração tal que implicava em problemas no que tange à capacidade de atuação conjunta e, consequentemente, para a efetivação do processo de jointness, dado o contex to onde a lógica de maximização de interesses individuais preponderava.

Tendo tudo isso em vista, depreende-se que a instituição passou por uma importante trajetória até a implementação de fato do decreto que estabelece novas diretrizes para a ação militar, uma vez entendido que jointness já vinha sendo considerado e buscado por diversos anos desde o governo Truman e Eisenhower (Correll 2011). É possível perceber, inclusive, que essa trajetória não se deu de forma estável, e sim a partir de uma perspectiva mais dinâmica da instituição que, através da observação e do aprendizado das operações militares que fracassaram, possibilitou a busca pela reforma. Viu-se possível, a partir do lado de quem a demandava, que a mudança institucional levaria a benefícios militares que até então, sem a aplicação de fato do jointness, não se percebia alcançar.

A partir da lógica da mudança gradual, o DoD dos EUA instituiu o novo decreto que reordenava o planejamento e o emprego nas suas 
forças militares. Tal ímpeto partiu também de fontes endógenas, ${ }^{14}$ visto na fala do Chefe do Estado-Maior Conjunto, David Jones, à Comissão Parlamentar de Assuntos Militares. Ali, esse outro ator importante no processo de institucionalização de jointness argumentou que, frente a problemas no sistema, ele tentou realizar uma reforma, porém fracassou. Dependia então do Congresso, incitado pelo posicionamento de Jones, o estabelecimento da reforma (Marquis et al. 2017; Pires et al. 2018). Além disso, ocorreu também de forma bastante lenta, como pontuado por Armstrong (1995). Com base no argumento de Broderick (1970), conforme citado por March e Olsen (2007), inclusive afirmam que as percepções de que as mudanças nas estruturas de uma instituição só ocorrem a partir de um choque externo, o que acaba por subestimar o fato de que pressões internas para reformas serem realizadas são comuns quando o ideal institucional não corresponde na prática.

Quando aplicado ao modelo de Mahoney e Thelen (2009) sobre as dimensões da mudança institucional, é possível aproximar a reforma no Departamento ao layering, pois não há exatamente a substituição de regras antigas. Ao invés disso, a reforma incorpora novas regras que se somam a elas, buscando enfatizar doutrinas e estratégias conjuntas, sem excluir as particularidades de cada um dos ramos (Trainor 1993). Assim, na era do jointness é possível afirmar que os poderes individuais do Exército, da Aeronáutica, da Marinha e dos Fuzileiros Navais foram reduzidos, em prol de uma estrutura unificada à qual todas as forças passaram a pertencer e obedecer, diferenciando de antes, quando o que se podia perceber era cada um dos serviços, de maneira individual, constituindo-se como o centro do poder no DoD (Correll 2011, 1).

A cadeia de comando, desde o Presidente ao Secretário de Defesa e os Comandantes de combate, se viu transformada (Carter 2016). Os chefes das forças singulares costumavam desempenhar funções de aconselhamento militar, contudo, com o GNA, a função de aconselhamento militar aos líderes civis passa a estar centralizada na figura do Presidente do Joint Chiefs of Staff (Nemfakos et al. 2010). Assim, o Presidente do Estado-Maior Conjunto está além da cadeia de comando, de forma que "pudesse fornecer conselhos militares vitais, objetivos e independentes ao Secretário de Defesa e ao Presidente” (Carter 2016, 1, tradução nossa). Isto aumenta a sua habilidade no sentido de tomar a frente de estratégias gerais, além de dotar-se de maior autoridade para buscar unificar os comandantes das forças singulares e, consequentemente, diminuindo as responsabilidades desses comandantes de maneira individual (Nemfakos et al. 2010). 


\section{Quadro 1}

Antes e o depois do Goldwater-Nichols Act no que tange as principais funções desempenhadas

\begin{tabular}{|l|l|}
\hline \multicolumn{1}{|c|}{ Antes do GNA } & \multicolumn{1}{c|}{ Após o GNA } \\
\hline Diversas cadeias de comando; & Estrutura passa a ser unificada; \\
$\begin{array}{l}\text { Forças singulares dotadas de poder } \\
\text { individual e de aconselhamento; }\end{array}$ & $\begin{array}{l}\text { As forças singulares agora respondem ao Joint } \\
\text { Chiefs of Staff; o Presidente do órgão passa a ser } \\
\text { responsável pelo aconselhamento militar às auto- } \\
\text { Coordenação e Comunicação fracas. } \\
\text { ridades civis; } \\
\text { Unificação dos comandantes das forças singu- } \\
\text { lares passa a ser competência do Estado-Maior } \\
\text { Conjunto. }\end{array}$ \\
\hline
\end{tabular}

Fonte: Elaboração própria com base em Correll (2011), Nemfakos et al. (2010) e Carter (2016).

Pretende-se assim mostrar, portanto, que apesar da prática de operação conjunta já existir há bastante tempo, tendo uma retomada mais forte após a Segunda Guerra Mundial, a forma como as executavam e a maneira como o DoD se organizava travavam uma coordenação e integração de fato. Em um órgão em que antes se via um estado de independência entre os serviços, após o GNA o DoD mostrou-se mais centralizado (Marquis et al., 2017). O decreto mais do que meramente substituiu regras; acresceu algumas no sentido de melhorar a interoperabilidade entre as forças singulares, convergindo assim com o que Mahoney e Thelen (2009) entendem por layering, e com o que March e Olsen (2007) entendem por learning, um dos processos de mudança, que é quando atores buscam realizar reformas com base em feedbacks a partir de experiências passadas. Além disso, Mahoney e Telen (2009) em alguma medida dialogam com o objeto do presente trabalho quando consideram que a mudança institucional pode ocorrer também a partir de problemas relacionados à interpretação e ao enforcement de uma regra já existente - fazendo com que atores busquem implementar aquelas regras de novas formas, como foi o que pode ser visto com a busca pela coordenação e integração entre as forças singulares dos EUA.

O ímpeto pela reforma do DoD decorreu da observação de experiências militares já vivenciadas, sendo este o estímulo principal para a iniciativa de se institucionalizar o processo de jointness, operação militares que não foram bem-sucedidas e serviram como processo de aprendizado para a instituição do desenvolvimento das capacidades conjuntas das forças singulares. Além disso, como colocado por Putnam (2005), as práticas insti- 
tucionais estariam diretamente relacionadas a todo um contexto social ao qual estas se inserem. No caso do DoD, as práticas institucionais estariam atreladas ao contexto inerentemente militar, onde as forças singulares tendem a priorizar interesses próprios. Por isso, fala-se da importância do contexto, uma vez que o desempenho de uma instituição depende deste.

Um dos elementos mais colocados, quando analisado o processo de jointness dentro de uma instituição militar, diz respeito às capacidades e personalidades dos atores envolvidos. É possível analisar-se a questão da reforma que ocorreu através do GNA a partir da observação das relações civis-militares, principalmente no que diz respeito a tomada de decisão. Aqui busca-se enfatizar problemas relacionados aos analistas civis que respondiam diretamente ao Secretário de Defesa e, por outro lado, os militares munidos pelo instinto e pela experiência. "Um time de atores que não estavam acostumados a trabalhar uns com os outros, nem compartilhavam do mesmo ponto de vista, além de não terem internalizado nenhuma base para respeito e confiança mútuas" (LoPresti 1991, 49, tradução nossa). E, como já salientado, os militares receberam com bastante resistência as propostas dos Senadores Nunn e Goldwater quando do início do processo que instituiria a legislação responsável pela reforma no Departamento de Defesa.

Todos esses elementos somados tornam clara a razão de ser difícil tratar de mudança institucional, pois esta compreende diversos componentes que interagem e que, por muitas vezes, dificultam o próprio processo de mudança, uma vez que existem atores que possam preferir a estabilidade, enquanto outros podem preferir a mudança.

\section{CONSIDERAÇOES FINAIS}

Ao investigar instituições, é importante que a análise seja realizada a partir de diversas óticas, permitindo assim uma maior abrangência de observações. Os neo-institucionalistas buscam fornecer esse aparato como forma de abarcá-las (Nascimento 2009). No que tange à mudança institucional, analisar o processo histórico que levou uma instituição a adotar determinada mudança é crucial para o entendimento sobre o que teria levado ao surgimento da necessidade da reforma, uma vez que, como apresentado pela literatura sobre instituições, na maioria dos casos a estabilidade vai ser preferível. Portanto, assim se explica a análise da trajetória histórica dos Estados Unidos ao longo de terminado período, para entender justamente quais fatores levaram à implementação do jointness como processo essencial dentro do âmbito militar. Tendo em vista, como colocado por Steinmo (2008), que a história é composta por eventos dependentes, e a sua compreensão facilitaria assim a análise institucional. 
Conforme o que foi apresentado ao longo do artigo, e com base na literatura de apoio, é possível afirmar que, para que inovações ocorram nas instituições, é necessário que haja mudanças. Portanto, buscou-se visualizar para além das mudanças abruptas que ocorrem a partir de choque externos, dando enfoque a um modelo menos dramático, que ocorre de maneira mais lenta e em partes. Assim, entende-se que a mudança gradual/ incremental tem tantas consequências e importância quanto a mudança abrupta (Mahoney and Thelen 2009). As instituições relacionadas à defesa possuem aspectos próprios que não podem ser negligenciados (Pessoa and Freitas 2015), e que têm relevantes consequências e capacidade de moldar resultados políticos.

A implementação do Goldwater Nichols Act no legislativo e como uma reforma direta no DoD teve desdobramentos institucionais bastante importantes. A partir de uma análise com foco na mudança institucional, percebeu-se que os aspectos relevantes nesse cenário se concentram principalmente no problema da rivalidade intraforças e no paroquialismo, diretamente relacionados com a questão da cultura específica de cada uma das Forças, pois levaram a uma falta de coordenação em diversas operações militares e acabaram permitindo ser identificada a necessidade de institucionalizar o processo de jointness de modo que fosse imposto na vivência militar, desde o planejamento até o emprego das Forças Armadas.

A mudança ocorrida dentro do Departamento está mais relacionada com o argumento de Mahoney e Thelen (2009) sobre a mudança ser gradual. Ocorreram fatos históricos que permitiram o reconhecimento da necessidade da mudança, no entanto esta não teria se dado de forma repentina, e sim de modo paulatino e incremental, por meio da tentativa de colocar em prática um aprendizado observado ao longo do tempo, até ser implementado de fato o Goldwater-Nichols Act.

Por fim, finaliza-se elencando outra característica institucional bastante relevante nesse contexto, que foi a identificação de prováveis atores favoráveis e atores contrários à mudança no Departamento. Inicialmente, de um lado estavam os senadores que propuseram a reforma, pautados pelo argumento de que faltava às Forças Armadas estadunidenses coesão e coordenação interna, tendo por base experiências passadas que foram frustradas, enquanto de outro lado foi possível de serem percebidos atores no setor militar que representaram, inicialmente, entraves à mudança, por receio de terem suas preferências minimizadas - estando esses aspectos relevantes diretamente relacionados com a questão da Cultura Organizacional e da Mudança Militar também atreladas ao paroquialismo, e que faziam crescer a percepção de que uma reforma seria necessária e que o poder deveria estar centralizado no Joint Chiefs of Staff ao invés de ser canalizado nos 
comandos das forças singulares, como forma de priorizar muito mais uma gestão conjunta que até então se mostrava precária.

Salienta-se a importância do estudo, uma vez reconhecido que o processo de pesquisa acerca de mudança institucional ainda permanece bastante subteorizado, às margens do campo de estudo das instituições (Dixit 2009, apud Brousseau et al. 2011). Pontua-se, portanto, a importância das bifurcações, ou seja, a relevância de entender que em alguns casos pode não haver exatamente uma continuidade em relação ao que era, criando-se assim um novo trajeto (Hall and Taylor 2003), para mostrar que as mudanças quando ocorrem podem ser originadas também através de um processo gradual e incremental, o que não têm sido exatamente um foco nas ciências sociais, como pontuado por Mahoney e Thelen (2009), e não apenas a partir de um choque exógeno que interrompe a continuidade de um processo institucional, calcado no equilíbrio pontuado, sendo assim decorrentes de variáveis endógenas.

Neste trabalho, tentou-se, além de elucidar a questão central da pesquisa, contribuir para o entendimento sobre as diversas possibilidades de interpretação abertas a partir da análise da mudança institucional, facilitada através da reforma de 1986 no Departamento de Defesa dos Estados Unidos, com base nos novos institucionalismos previamente citados, o da escolha racional, o sociológico e o histórico. E, em alguma medida, quem sabe, contribuir para aprofundar os estudos sobre mudança institucional no Brasil, o que ainda vêm sendo construído.

\section{REFERÊNCIAS}

Armstrong, David. 1995. “Jointness and the Impact of the War.” JFQ(Summer): $36-37$.

Broderick, A. (Ed.) 1970. The French Institutionalists. Maurice Hauriou, Georges Renard, Joseph Delos. Cambridge, Mass.: Harvard University Press.

Brousseau, Eric, Pierre Garrouste, and Raynaud Emmanuel. 2011. "Institutional changes: Alternative theories and consequences for institutional design." Journal of Economic Behavior E Organization 79: 3-19.

Carter, Ash. 2016. "Remarks on 'Goldwater-Nichols' at 30: An Agenda for Updating”. Washington, D. C. 5 de abril. https://www.defense.gov/Newsroom/ Speeches/Speech/Article/713736/remarks-on-goldwater-nichols-at-30-an-agenda-for-updating-center-for-strategic/.

Correll, John. 2011. "The Campaign for Goldwater-Nichols.” Air Force Magazine. 29 de setembro. https://www.airforcemag.com/article/1011 campaign/. 
Dixit, A. 2009. Governance Institutions and Economic Activities. American Economic Reviere, no. 99: 5-24.

Estados Unidos (EUA). 1986. Goldwater-Nichols Department of Defense Reorganization Act of 1986. Lei pública 99-433-oct. 1. https://history.defense.gov/ Portals/70/Documents/dod_reforms/Goldwater-NicholsDoDReordAct 1986. pdf.

Estados Unidos (EUA). 2016. 10 U. S. Code $\$ 151$. Joint Chiefs of Staff: composition; functions. https://www.law.cornell.edu/uscode/text/10/151.

Gomide, Alexandre. 2014. "Tipos e Dinâmicas de Mudança Institucional: as agências reguladoras de transportes no Brasil”. Revista de Ciências Sociais 57, no 3: 855-85. Rio de Janeiro.

Hall, Peter, and Rosemary Taylor. 2003. "As três versões do neo-institucionalismo." Lua Nova 58: 193-223.

Hamre, John. 2016. "Reflections: Looking back at the need for Goldwater-Nichols." Center for Strategic \& International Studies, 27 de janeiro. https://www.csis.org/ analysis/reflections-looking-back-need-goldwater-nichols.

LoPresti, Thomas. T. 1991. "The JCS System before and after Goldwater-Nichols Act.” Georgetown University: Waskington D. C. (May): 1-58.

Mahoney, James, and Kathleen Thelen. 2009 "A Theory of Gradual Institutional Change". In Explaining Institutional Change: Ambiguity, Agency, and Power, edited by James Mahoney, and Kathleen Thelen: 1-37. Cambridge University Press. Cambridge, UK.

March, James G., and Johan P. Olsen. 2007. "Elaborating the "New Institutionalism". In The Oxford Handbook of Political Institutions, edited by R. A. W. Rhodes, Sarah A. Binder, and Bert A. Rockman: 3-20. Oxford University Press.

Marquis, Christopher, Denton Dye, and Kinkead Ross. 2017. "The Advent of Jointness During the Gulf War: A 25-year retrospective.” JFQ 85, $2^{\text {nd }}$ quarter: $76-83$.

McInnis, Kathleen J. 2016. "Goldwater-Nichols at 30: Defense Reform and Issues for Congress.” Congressional Research Service. June $2^{\text {nd: }}: 1-60$.

Nascimento, Emerson O. do. 2009. "Os novos institucionalismo na ciência política contemporânea e o problema da integração teórica". Revista Brasileira de Ciência Política, no. 1 (Janeiro-Junho): 95-121. Brasília. 
Nemfakos, Charles, Irv Blickstein, Aine Seitz McCarthy, and Jerry M. Sollinger, 2010. "The Perfect Storm: The Goldwater-Nichols Act and it effect on Navy acquisition." California: RAND Corporation: 1-59.

Österberg, Major V. 2004. "Military theory and the concept of Jointness.": 4-44.

Pessoa, Tamiris. 2017. A formação de oficiais e as operações conjuntas: comparações com o caso britânico e os desafios brasileiros de gestão em defesa. Tese de doutorado, Universidade Federal do Rio Grande do Sul, Porto Alegre.

Pessoa, Tamiris S., and Marco T. D. Freitas. 2015. "A adoção do modelo joint: reflexões sobre implicações no modelo brasileiro.” R. Esc. Guerra Naval 21, no 2 (Jul./Dez.): 203-220. Rio de Janeiro.

Piffer, Marcus. 2014. Operações Conjuntas: desafios à integração no nível operacional. Dissertação de mestrado. Escola de Comando e Estado-Maior do Exército. 129f. Rio de Janeiro.

Pires, Gustavo Calero Garriga, Hercules Guimarães Honorato, and Rejane Pinto Costa. 2018. A importância da Reforma Goldwater-Nichols para a Evolução da Interoperabilidade nas Forças Armadas dos Estados Unidos da América. Revista da Escola Superior de Guerra33, no. 69 (Set./Dez.): 198-220.

Putnam, Robert. 2005. "Introdução: estudo do desempenho institucional". In Comunidade e Democracia: a experiência da Itália moderna. 4. ed.: 19-31. Rio de Janeiro, RJ: Fundação Getúlio Vargas.

Rearden, Steven L. 2012. "Preface" In Council of War: A History of the Joint Chiefs of Staff. 1942-1991. NDU Press. Joint History Office.

Snider, Dom M. 1996. "The US Military in Transition to Jointness". Air and Space Power Journal (Fall): 16-27. Alabama.

Sloan, Elinor C. 2008. Military Transformation and Modern Warfare: a reference handbook. Westport: Praeger Security International.

Steinmo, Sven. 2008. "Historical Institutionalism”. In Approaches and Methodologies in the Social Sciences: A Pluralist Perspective, edited by Donatella della Porta, and Michael Keating. Cambridge University Press.

Thelen, Kathleen. 1999. "Historical Institutionalism in Comparative Politics." Annual Review of Political Science 2: 369-404. 
Thelen, Kathleen, and James Conran. 2016. "Institutional Change". In: The Oxford handbook of Historical Institutionalism, edited by Orfeo Fioreto, Tulia G. Falleti, and Adam Sheingate. Oxford U. Press.

Trainor, Bernard. E. 1993. "Jointness, service culture, and the Gulf War." JFQ (Winter): 71-4. Washington.

U.S. Department of Defense. 2020. "About the Department of Defense (DoD)." https://archive.defense.gov/about/.

Vitale, Michael. C. 1995. “Jointness by Design, Not Accident.” JFQ (Autumn): 24-30. Washington.

Weyland, Kurt. 2008. "Toward A New Theory Of Institutional Change." World Politics 60, no. 2: 281-314.

Wilkerson, Lawrence B. 1997. "What exactly is Jointness?” JFQ (Summer): 1-3. Washington. 


\section{NOTAS}

1. Este se trata de um processo que tem por central tornar as operações militares conjuntas mais efetivas (Vitale 1995), onde por conjunta entende-se um tipo de configuração que preconiza a ação de mais de uma força armada, por exemplo, Marinha, Exército e Força Aérea.

2. Representa um "movimento" que teve início com militares soviéticos na década de 1970, cujo pensamento estratégico sobre uma revolução técnica militar começou a ser desenvolvido (Sloan 2008).

3. Interoperabilidade diz respeito à medida pela qual organizações e indivíduos conseguem atuar de forma conjunta para se alcançar um mesmo objetivo; além disso, dentre os elementos de jointness é um dos mais fundamentais (Wilkerson 1997).

4. Trata-se de algo oficial, como leis, regulamentos e ordens políticas, que geralmente surgem a partir de negociações (Brousseau et al. 2011).

5. Os teóricos dessa abordagem defendem que as estratégias, dentro de um contex to institucional particular, se perpetuariam ao longo do tempo, caindo em um processo que dá continuidade e encoraja determinadas preferências (Hall and Taylor 2003).

6. Aqui, inclusive, pode ser pontuada a forma como jointness nos Estados Unidos veio a se tornar um modelo a ser seguido. O Brasil, por exemplo, fundamenta a sua discussão sobre doutrina a partir da experiência estadunidense (Piffer 2014), incorporando conceitos e aspectos que se aproximam em algum grau do modelo adotado pelo Estados Unidos. É o que o Weyland (2008) chama de impulso por emulação com base em experiência de terceiros, e que está diretamente relacionado ao institucionalismo da escolha racional.

7. Isto é, há uma tendência de se perpetuar comportamentos e padrões institucionais por um longo período, com base em um arcabouço histórico (Mahoney and Thelen 2009).

8. "Períodos de contingência, durante os quais as restrições usuais à ação são suspensas ou facilitadas" (Mahoney and Thelen 2009, 7, tradução nossa): quando uma conjuntura é capaz de interromper a estabilidade da instituição.

9. Nesse contexto, a evolução tecnológica que teve início a partir da Revolução dos Assuntos Militares e que contribuiu largamente para a instituição das operações conjuntas, começou a se desenvolver (Pessoa 2017).

10. Esse órgão seria o equivalente ao Estado Maior Conjunto das Forças Armadas no Brasil, isto é, o corpo responsável por executar o planejamento do emprego conjunto das forças, e por, entre outras coisas, gerir a interoperabilidade (Pessoa 2017). 
11. Algumas outras situações também foram importantes para o processo pela busca da instituição do jointness, como, por exemplo, a Guerra do Vietnã (Nemfakos et al. 2010), e um outro episódio de bombardeamento de quarteis estadunidenses no Beirute (McInnis 2016), contudo, a título de recorte e visto que estas duas ocasiões em especial levaram de modo mais cabal a essa busca, optou-se por focar de maneira um pouco mais detalhada nas citadas.

12. Ainda dentro do modelo de Mahoney e Thelen (2009), é possível associar a figura dos senadores ao tipo de agentes da mudança tido por subversives, onde estes, para conseguirem realizar a mudança pretendida, o fazem de maneira que não quebre regras anteriores, dialogando com o próprio sistema, enquanto buscam incentivar novas regras à margem das antigas.

13. A busca por favorecimento individual dos ramos das Forças Armadas (Pessoa 2017).

14. Apesar da reforma ter ganhado forma no parlamento dos EUA (Pires et al. 2018), é importante que sejam reconhecidos a influência dos incentivos realizados pelo General Jones no âmbito interno do DoD. 


\section{UMA ANÁLISE NEO-INSTITUCIONAL DA ADOÇÃO DE JOINTNESS} PELOS ESTADOS UNIDOS

\section{RESUMO}

A adaptação das Forças Armadas dos Estados nos diversos contextos apresentados pelo cenário internacional vem adquirindo maior relevância. Em consonância, o princípio de jointness ressurgiu como elementar dentro dos assuntos de Defesa, visto que trabalhar as forças em torno de conceitos como a interoperabilidade e a sinergia é parte do processo de adaptação. Entretanto, poucos trabalhos na área se focam no estudo das instituições de Defesa e, em especial, em seus processos de mudança institucional. Desta forma, tendo por tema a ótica de jointness e a mudança institucional, foi abordado o seguinte problema: "como as teorias neo-institucionalistas, à luz da mudança institucional, explicariam a reforma promovida, em 1986, no Departamento da Defesa dos Estados Unidos?”. No que tange ao procedimento metodológico, optou-se pela realização de um estudo de caso, o que permitiu que se chegasse à conclusão de que, tanto a partir de estímulos quanto de entraves internos, o processo da mudança dentro do Departamento se deu de maneira gradual e incremental.

Palavras-chave: Mudança Incremental; Instituições; Jointness; Estados Unidos.

\section{ABSTRACT}

The adaptation of the Armed Forces of the States in the different contexts presented by the international scenario has been acquiring greater relevance. Accordingly, the principle of jointness has reappeared as an element in defense matters since working with the different armed forces around concepts such as interoperability and synergy is part of the adaptation process. However, few studies in the area focus on the study of Defense institutions and, in particular, on their processes of institutional change. Therefore, having jointness and institutional change as the main theme, the following problem was addressed: "how neo-institutionalist theories, in the light of institutional change, would explain the reform promoted in 1986 in the United States Department of Defense?”. Regarding the methodological procedure, a case study was chosen, which allowed the conclusion that: both from internal incentive and barries, the process of change within the Department took place gradually and incrementally.

Keywords: Incremental Changes; Institutions; Jointness; United States.

Recebido em 13/11/2019. Aceito para publicação em 18/08/2020. 